\title{
Barriers of Cross-Cultural Communication among Foreign Managers and Staff in Interacting with Malaysian Counterparts
}

\author{
Ahmad Arifin Bin Sapar \\ Department of Arabic Language, Faculty of Languages and \\ Linguistics University of Malaya \\ Kuala Lumpur, Malaysia \\ Syarif Hidayatullah State Islamic University Jakarta, \\ Indonesia \\ arifindum. edu.my
}

\begin{abstract}
The main aim of this study is to investigate language and cultural barriers of intercultural communication among foreign managers and staff (expatriates) in interacting with their Malaysian counterparts at University of Malaya. Language and culture are fundamental barriers hindering the flow of crosscultural communication between expatriates and their Malaysian counterparts. This study has used grounded theory research methodology equipped with deep qualitative analysis, and technique of data analysis in accordance with the semi-structure interviews. Data has been analyzed qualitatively in order for the researchers to provide deep analysis and understanding for the phenomenon under investigation. The study concluded that there are two main themes generated under the language barrier and culture barrier. English proficiency, body language, poor speaking and listening skills and indirect communication styles are due to linguistic barriers; while body language, miscommunication and ethnocentrism are due to cultural barriers. The results of the study would increase the organizational performance, equilibrium and academic success. Thus, the study may add insightful knowledge and findings to the existing literature.
\end{abstract}

Keywords-- Barriers; cross-cultural; intercultural communication; language barrier; cultural barriers; expatriates.

\section{INTRODUCTION}

The main aim of this study is to investigate challenges and barriers of intercultural communication that foreign managers and staff face while interacting with their Malaysian counterparts at University of Malaya (UM). Culture is defined as a way of life, a set of shared values, attitudes, goals and practices. Hofstede [1] defines culture as a "collective programming of the mind that distinguishes the members of one group or category of people from another". Language is the means by which communication takes place and allows us to create a common meaning about the world. Verbal and nonverbal communication is another crucial factor that plays an essential role in influencing the planned actions and outcomes

\author{
Shehda R.S AbuIsaac \\ Department of English Language, \\ Faculty of Languages and Linguistics, University of Malaya \\ Kuala Lumpur, Malaysia \\ Syarif Hidayatullah State Islamic University Jakarta, \\ Indonesia \\ Bright.1990@hotmail.com
}

of a workplace, where people from different cultural and ethnic backgrounds work together. Formal communication is controlled by a set of rules and standards that all members working at the same workplace should follow. Informal communication, on the other hand, as interlocutors are not bound to a rigid set of rules while conversing; they however, "modify what they have to say in order to deal with someone else's objections or misunderstanding" [2].

In an interesting study about communication across cultures in multinational Ibis West Africa, Abdulai, Ibrahim \& Mohammed [3] qualitatively investigated the interaction and intercultural communication between local workers (Ghanaians) and expatriate workers. They concluded that there are misunderstandings, misinterpretations and misperceptions of both verbal and non-verbal messages as well as differences in creating meaning of messages decoded and encoded. Within the Malaysian context of the factors affecting intercultural communication between students and staff, Krishnasamy, Hussein and Dalib [4] conducted a study about intercultural interaction experiences of international students and local instructors at University Utara of Malaysia. They interviewed 25 Arab students. They concluded that: 1- intercultural communication is affected by misuse of words and vocabulary and misinterpretation of words on the part of Arab students. 2They also state such language problems are potential barriers to intercultural communication. Ismail, Che Noh and Omar [5] conducted a study about how taboos create barriers for crosscultural communication between the main ethnic group (Malays, Chinese, and Indians) in Malaysia. They concluded that: 1- barriers of cross-cultural communication are caused due to taboo words and topics concerning religion. 2-Some Malaya personnel are not aware of the fact that there are some taboos that they do not understand about other ethnicities. The main issue of this study is that there are challenges and barriers that hinder cross-cultural communication between foreign managers 
and staff and their Malaysian counterparts at UM. These challenges and barriers need to be examined so as to communication problems concerning language and culture may be overcome and therefore a tranquil atmosphere takes place at diverse workplace. This study would increase the organizational performance, equilibrium and academic success. To the best of our knowledge, there may be no study that has yet investigated the co-relation between barriers of intercultural communication and cross-cultural adjustment and its impact on the organization performance and equilibrium. To achieve the main purpose of the study, we will try to answer these two main questions: 1what are the linguistic barriers and challenges that foreign managers and staff face while interacting with their Malaysian counterparts? and 2- what are the cultural barriers and challenges that foreign managers and staff face while interacting with their Malaysian counterparts?

\section{METHOD}

The data collection took place at University of Malaya. Five foreign participants were interviewed at University of Malaya, three academic staff and two managers. The study used a qualitative research approach in analyzing and interpreting the data. A descriptive case study was applied, and so all respondents were interviewed in one-to-one semi structured interview.

\section{RESULT AND DISCUSSION}

In this section, the data will be first classified then analyzed and discussed under main themes and sub-themes as follows.

\section{A. Language Proficiency (English As the Main Means of Communication)}

Three respondents out of five stated that language barriers are crucial while they communicate and interact with their Malaysian counterparts. This in most cases leads to misunderstanding and discomfort at workplace. A senior lecture stated that "If we speak with their language, they feel comfortable, happy. If we do not speak their language they pay no attention to you, leave your file and may try to get rid of you". This indicates that language plays a fundamental role in hindering the flow of friendly communication between foreign managers and staff and their Malaysian counterparts.

Besides that other basic language skills still cause a problem when foreign managers and staff mingle with their Malaysian counterparts. For example, a foreign manager states that "their speaking and listening skills are not good". Another issue stated by the expatriates is that management in UM sends emails to them in Malay language. "They send emails to us in Malaya language. They are not aware that we are foreigners. This is the main barrier!" (Associate professor) This makes them misunderstand the message and even in many cases not to be encouraged to open and read the message, therefore, some important information or requests are lost, which increases managerial problems between expatriates and local management.

\section{B. Code-switching}

Code switching is another barrier hindering the flow of friendly interaction and communication between expatriates and local management. "My staffs mix English with Malay, which would leads to some misunderstanding. For example, they add "la" in their words, e.g. okay becomes okayla".

\section{Body Language}

Body language is a crucial challenge that expatriates in general face while interacting and mingling with local staff and managers. "As far body language is considered, in my opinion, it is crucial and lead to a serious misunderstanding and misinterpretation" (manager1) Manager (2) states his own experience using body language while communicating with his Malaysian counterparts. He states that "their communication style is different and they try their best to make you understand, however, because their culture is a high context culture, certain things remain untouched".

\section{Body Language and Culture}

Body language in relation with culture causes the main challenges and barriers hindering the flow of peaceful and friendly interaction and communication between expatriates and their Malaysian counterparts. One manager states that "loud voice and over action is considered impolite and be interpreted as aggressive behaviors, while in our culture is the opposite". Another manager, on the other hand, stated that "they read us as they want based on their psychological perception, not based on reality and reason; they even expect us to know how to address them based on their social status". These issues are serious in hindering a peaceful communication at the diverse workplace; and in most cases the reason of this is due to Malaysian counterparts' culturalbound realization and perception of understanding and interpreting things.

\section{E. Miscommunication Attributed to Culture}

Culture is the cornerstone formulating and conveying the way people communicate. Miscommunication takes place among expatriates and their Malaysian counterparts when there are culture-bound symbols and signs and verbal expressions that are idiosyncratic to the social and cultural norms rooted in one ethnic social group. "Miscommunication is not considered as a miscommunication, however it is considered as a unique part of the Malaysian culture. Skillful employees resign instead of solving the problem and fighting back- they just leave." 
(manager 2) This resignation and fast- making decisions made by local employees while they were being managed by foreign managers is that they misunderstand and interpret things according to their culture. The manager stated an example of what had happened to him with his local employee "one of my employees, the secretary, did not like something about the work. I do not know what this something is, she started to come late and then excuse herself from coming to work and in the end she asked for resignation. She never spilled it out and opened a room for discussion to solve the problem". Also, cultural-based hints are communication means by which Malaysian employees use to indicate that they are not happy about the work and therefore they come late and start raise some family issues as a "pre-stage detection alarm". According to Malaysian culture, science is a culture-based norm that affects workplace and successful performance. This is because Malaysians do not talk about person issues concerning their situation at workplace and therefore the scenario becomes worse.

\section{F. Ethnocentrism}

Ethnocentrism is a crucial factor hindering successful communication between expatriates and their Malaysian counterparts. In many cases, expatriates state that their Malaysian counterparts expect them to know their culture norms, social hierarchy and to imitate the way they communicate and deal with things. "To be attentive and entertaining in Malaysian culture is considered wrong" (manager 2).

\section{CONCLUSIONS}

The study concluded that there is a serious miscommunication issue between expatriates and their Malaysian counterparts at UM. This is due to linguistic and cultural barriers that differentiate ways of thinking, work, handling problems and management styles between the expatriates and their Malaysian counterparts. As far as linguistic barriers are concerned the study concluded that lack of English proficiency hinders the flow of successful communication between expatriates and their Malaysian counterparts. Another linguistic barrier is code-switching and most importantly body language, which both play a crucial role in hindering crosscultural communication. Body language is found to be discursive including silent language, indirect language and facial symbolic language which, if not carefully and correctly used in communication, hinder cross- cultural communication. As far as cultural barriers are concerned, the study concluded that cross-cultural understanding is a powerful challenge that has an extreme effect in hindering cross-cultural communication. Body language and miscommunication are found to be highly influenced by culture. Ethnocentrism is also an issue hindering the flow of friendly successful cross- cultural communication between expatriates and their Malaysian counterparts.
Despite all these challenges and barriers, there are some solutions recommended by the participants. Some of these solutions are that expatriates should learn the local language, learn how to address people and learn important cultural norms. Finally, the study recommends that 1- UM management should conduct intensive courses concerning language and culture for both expatriates and Malaysian counterparts before they start mingling with each other at work place, 2- UM should hire new staff based on their cultural and linguistic proficiency and 3Both expatriates and their Malaysian counterparts should study culture and social norms of more than one ethnic group. This may broaden the gap and leads to a successful performance at workplace

\section{REFERENCES}

[1] G. Hofstede, G, Cultures and organizations: Software of the mind: Intercultural cooperation and its importance for survival. New York: McGraw Hill, 1996.

[2] R. E. Kraut, H. S. Lewis, and W. L. Swezey. "Listener responsiveness and the coordination of conversation," Journal of personality and social psychology, vo. 43, no, 4, p. 718., Oct, 1982.

[3] M. Abdulai, H. Ibrahim and M.A. Mohammed, "Communicating across cultures in multinational Ibis West Africa," International Journal of Intercultural Relations, vol. 31, no. 58, pp. 42-53, May 2017.

[4] H.N. Krishnasamy, M.H. Hussein, and S. Dalib, "Intercultural Interaction Experiences in a Tertiary Level Institution in Malaysia." Procedia-Social and Behavioral Sciences, vol. 155, pp.465-470, 2014.

[5] I.R. Ismail, C.H. Noh, K, Omar, "Knowing the Taboos, Improve Intercultural Communication: A Study at Terengganu, East Coast of Malaysia," Procedia-Social and Behavioral Sciences, vol. 219, pp 359-66, May 2016. 